DE

M E D I C I N A

T R O P I C A L

$\mathrm{DE}$

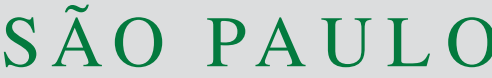

JOURNAL OF THE SÃO PAULO INSTITUTE OF TROPICAL MEDICINE

${ }^{1}$ Universidade Federal de Pelotas,

Programa de Pós-Graduação em

Biotecnologia, Pelotas, Rio Grande do Sul,

Brazil

2Universidade Federal de Rio Grande, Núcleo de Pesquisas em Microbiologia Médica, Rio Grande, Rio Grande do Sul, Brazil

${ }^{3}$ Hospital Universitário São Francisco de Paula, Setor de Endoscopia Digestiva, Pelotas, Rio Grande do Sul, Brazil

Correspondence to: Júlia Silveira Vianna Universidade Federal do Rio Grande, Núcleo de Pesquisas em Microbiologia Médica, Rua General Osório, s/n, CEP 96200-190, Rio Grande, RS, Brazil Tel: +55 53 32338895; Fax: +55 53 32338863

E-mail: jusvianna@ hotmail.com

Received: 7 March 2018

Accepted: 9 April 2018

\section{The interplay between mutations in cagA, $23 S$ rRNA, gyrA and drug resistance in Helicobacter pylori}

\author{
Júlia Silveira Vianna ${ }^{1,2}$, Ivy Bastos Ramis², Daniela Fernandes Ramos ${ }^{2}$, \\ Otávio Leite Gastal' ${ }^{3}$, Renato Azevedo da Silva ${ }^{3}$, Carla Vitola Gonçalves ${ }^{2}$, \\ Pedro Eduardo Almeida da Silva²
}

\section{ABSTRACT}

In this study, we evaluated the mutations of Helicobacter pylori associated with resistance to clarithromycin and levofloxacin. Furthermore, based on the proposed interaction between antimicrobial resistance and pathogenicity, we correlated the mutation profiles of the strains with the presence of the pathogenicity gene $\operatorname{cagA}$. We analyzed 80 gastric biopsy specimens from $H$. pylori-infected patients for point mutations in the $23 \mathrm{~S}$ rRNA gene region and in the gyrA gene, which are related to clarithromycin and levofloxacin resistance, respectively, and investigated the presence of the $\operatorname{cag} A$ gene in these strains. We observed that in the assayed biopsies, $8.7 \%$ (7/80) had mutations in the $23 S$ rRNA gene region at positions 2143 and 2142, while $22.5 \%$ (18/80) had mutations in $g y r A$ at codons 87 and 91 . Moreover, absence of the CagA-EPIYA pathogenicity factor was observed in $68 \%(17 / 25)$ of resistant samples. The knowledge of the local profile of antimicrobial resistance and the complex interplay involving resistance and pathogenicity can contribute to an appropriate clinical approach.

KEYWORDS: Antimicrobial resistance. Point mutations. Clarithromycin. Levofloxacin. CagA EPIYA.

\section{INTRODUCTION}

The successful treatment of patients infected with Helicobacter pylori can aid in prevention of serious gastroduodenal diseases, such as gastritis, peptic ulcers, adenocarcinoma and MALT (Mucosa-Associated Lymphoid Tissue). According to the Maastricht $\mathrm{V}$ Consensus, therapeutic regimens for eradication of this microorganism involve the use of combination therapy. Triple therapy, recommended as a first-line empirical treatment, uses a combination of amoxicillin (AMX) and clarithromycin (CLA) plus a proton pump inhibitor. However, in areas of high clarithromycin resistance (more than 15\%), quadruple therapy with bismuth is the recommended first-line treatment. As a rescue option, the second-line treatment is based on the use of levofloxacin $(\mathrm{LVX})^{1}$.

A high failure rate of anti-H. pylori therapy is observed, primarily due to the acquisition of point mutations by $H$. pylori that results in resistance to the antimicrobials CLA and LVX. This mechanism of resistance is related to the frequent and/or inadequate use of antimicrobials, which can place selective pressure on resistant strains. Regarding CLA resistance, an association of CLA resistance with the presence of mutations in the $23 S$ rRNA region has been described, especially at position $2143(\mathrm{~A} \rightarrow \mathrm{G})$ and $2142(\mathrm{~A} \rightarrow \mathrm{G})^{2}$. The resistance of $H$. pylori to LVX is associated with the presence of mutations in the gyrA gene, especially at codon 
Asn87 (substitution of asparagine by lysine) and Asp91 (substitution of aspartic acid by asparagine) ${ }^{3}$.

In addition to the resistance mechanisms developed by H. pylori against these antimicrobials, some studies have noted that the presence or absence of certain pathogenicity genes of bacteria and the gender and age of the patients are risk factors in the development of antimicrobial resistance ${ }^{4,5}$ There is evidence that the presence of the cagA (cytotoxinassociated gene $\mathrm{A}$ ) pathogenicity gene plays an important role in the induction of these severe gastric disorders. This is primarily due to the variable number of repetitive sequences of amino acids Glu-Pro-Ile-Tyr-Ala (EPIYA) in its 3' region, where it undergoes tyrosine phosphorylation, which may result in modulation of the inflammatory response $\mathrm{e}^{6}$.

Therefore, some studies have proposed the implementation of a molecular approach for gastric biopsy specimens of $H$. pylori in clinical practice since H. pylori exhibits slow growth and requires specific culture medium, making the phenotypic approach challenging and slow. Furthermore, molecular methods are capable of detecting the molecular basis of resistance and identifying pathogenicity genes ${ }^{7,8}$.

Thus, in this study, we analyzed mutations in $23 S$ rRNA and gyrA genes, which are related to resistance of a component of the first choice therapy, clarithromycin (CLA) and to the antimicrobial used as an alternative to standard therapy, levofloxacin (LVX), respectively ${ }^{2,3}$. In addition, we correlated this resistance with the presence of the pathogenicity gene $\operatorname{cag} A$ and with epidemiological factors of the patients included in the study.

\section{MATERIAL AND METHODS}

We analyzed 80 gastric biopsy specimens previously identified as $H$. pylori positive, obtained from upper digestive tract endoscopies of patients at the Sao Francisco de Paula University Hospital, in the city of Pelotas, Brazil. All patients provided informed consent and responded to a questionnaire. This study was approved by the Ethics Committee of the Universidade Catolica de Pelotas (registration $\mathrm{N}^{\circ}$ 658.179).

H. pylori infection was determined by histological analysis or by an in-house urease test and was confirmed by polymerase chain reaction (PCR). The histological analysis of the gastric biopsy was performed by HematoxylinEosin and Giemsa staining. For the in-house urease test, the biopsies were incubated in $1.0 \mathrm{~mL}$ of urea broth (Isofar, Brazil), prepared according to the manufacturer's instructions. The DNA was extracted from the biopsies, and the $g \operatorname{lm} M$ gene was PCR amplified to confirm the H. pylori infection, as previously described by Vianna et al. ${ }^{9}$.
The PCR-RFLP (Restriction Fragment Length Polymorphism) approach was used to investigate the mutations related to CLR resistance in the $23 S$ rRNA gene at positions 1342 to 1360 and 2765 to 2745 (complementary to the Escherichia coli homolog), which amplified an approximately 1,400 bp fragment. The fragment was digested with the restriction enzymes MboII and $B s a \mathrm{I}$ at $37^{\circ} \mathrm{C}$ for $2 \mathrm{~h}$ and $30 \mathrm{~min}$, to detect mutations at $\mathrm{A} 2142 \mathrm{G}$ and $\mathrm{A} 2143 \mathrm{G}$, respectively, as previously described $^{2}$. The mutations related to LVX resistance were explored by assessing the sequences at $H$. pylori positions 752601 to 752620 and 753182 to 753163 , which amplified an approximately 582 bp fragment of gyrA, as previously described ${ }^{3}$. The sequencing equipment was an ABI 3500 Genetic Analyzer, Life Technologies Applied Biosystems, used according to the manufacturer's instructions. Sequence alignment was performed using the BioEdit Sequence Alignment Editor, and sequences were compared to the genome of $H$. pylori 26695 by BLAST analysis.

The presence of the $\operatorname{cag} A$ gene was assessed by amplification of a variable region in the 3 ' portion of the coding region. The reactions yielded products of $500-850 \mathrm{bp}$ as follows: EPIYA AB, $500 \mathrm{bp}$; EPIYA-ABC, $640 \mathrm{bp}$; EPIYA-ABCC, $740 \mathrm{bp}$; and EPIYA-ABCCC, $850 \mathrm{bp}$, as previously described ${ }^{6,9}$.

Statistical analysis was performed by using the Fisher's Exact Test and the Chi-Squared Test. $P$ values of less than 0.05 were considered statistically significant.

\section{RESULTS}

Among the 80 samples from $H$. pylori positive patients included in the study, seven presented mutations in the $23 S$ rRNA region related to CLA resistance $(8.7 \%)$. Of these, $85.7 \%(6 / 7)$ had mutations at position 2143, followed by $14.3 \%(1 / 7)$ at position 2142 . Furthermore, in eighteen patients we identified mutations in the gyrA gene related to LVX resistance (22.5\%). We observed that 83.3\% (15/18) of the mutations in $g y r A$ were at codon 87 , while $16.7 \%$ (3/18) were at codon 91.

In addition, we investigated the association between H. pylori-positive patients with or without point mutations related to resistance to CLA or LVX with respect to sex, age, endoscopic diagnosis, previous treatment, drinking water source and the presence of CagA-EPIYA, as shown in Table 1. A statistically significant association was detected between mutations related to resistance with patients aged 45 years or more $(\mathrm{p}=0.024)$. Moreover, the absence of the pathogenicity factor CagA-EPIYA was observed in 68\% $(17 / 25)$ of resistant samples. 
Table 1 - Profile of $H$. pylori-positive patients resistant and not resistant to Clarithromycin (CLA) or Levofloxacin (LVX)

\begin{tabular}{|c|c|c|c|c|}
\hline & & $\begin{array}{l}\text { Not Resistant } \\
\qquad(n=55)\end{array}$ & $\begin{array}{l}\text { Resistant to CLA or LVX } \\
\qquad(n=25)\end{array}$ & $P$ value \\
\hline \multirow[t]{2}{*}{ Gender } & Female $(n=41)$ & $52.7 \%(29 / 55)$ & $48.0 \%(12 / 25)$ & \multirow{2}{*}{0.695} \\
\hline & Male $(n=39)$ & $47.3 \%(26 / 55)$ & $52.0 \%(13 / 25)$ & \\
\hline \multirow{2}{*}{ Age } & $\leq 45$ years $(n=34)$ & $50.9 \%(28 / 55)$ & $24.0 \%(6 / 25)$ & \multirow{2}{*}{0.024} \\
\hline & $>45$ years $(n=46)$ & $49.1 \%(27 / 55)$ & $76.0 \%(19 / 25)$ & \\
\hline \multirow{3}{*}{ Endoscopic Diagnostic } & Normal Mucosa $(n=3)$ & $3.6 \%(2 / 55)$ & $4.0 \%(1 / 25)$ & \multirow{3}{*}{0.819} \\
\hline & Gastritis $(n=54)$ & $65.5 \%(36 / 55)$ & $72.0 \%(18 / 25)$ & \\
\hline & Gastric Ulcer $(n=23)$ & $30.9 \%(17 / 55)$ & $24.0 \%(6 / 25)$ & \\
\hline \multirow{3}{*}{$\begin{array}{l}\text { Previous treatment } \\
\text { for } H \text {. pylori }\end{array}$} & No $(n=70)$ & $89.1 \%(49 / 55)$ & $84.0 \%(21 / 25)$ & \multirow{3}{*}{0.165} \\
\hline & $\leq 12$ months $(n=7)$ & $5.5 \%(3 / 55)$ & $16.0 \%(4 / 25)$ & \\
\hline & $>12$ months $(n=3)$ & $5.5 \%(3 / 55)$ & $0 \%(0 / 25)$ & \\
\hline \multirow{2}{*}{ Source of water to drink } & Public tap $(\mathrm{n}=68)$ & $81.8 \%(45 / 55)$ & $92.0 \%(23 / 25)$ & \multirow{2}{*}{0.237} \\
\hline & Mineral water $(n=12)$ & $18.2 \%(10 / 55)$ & $8.0 \%(2 / 25)$ & \\
\hline \multirow{3}{*}{ cagA-EPIYA } & No $(n=50)$ & $60.0 \%(33 / 55)$ & $68.0 \%(17 / 25)$ & \multirow{3}{*}{0.790} \\
\hline & $A B C(n=19)$ & $25.5 \%(14 / 55)$ & $20.0 \%(5 / 25)$ & \\
\hline & $\operatorname{ABCC} / \operatorname{ABCCC}(n=11)$ & $14.5 \%(8 / 55)$ & $12.0 \%(3 / 25)$ & \\
\hline
\end{tabular}

cagA EPIYA: cytotoxin associated gene A-Glu-Pro-Ile-Tyr-Ala

\section{DISCUSSION}

Although effective treatment regimens for $H$. pylori infections are available, the local antimicrobial resistance profile of strains should be considered. In the present study, $8.7 \%(7 / 80)$ of the samples presented a mutation in the $23 S$ rRNA region associated with CLA resistance, similar to the average ratio reported by other Brazilian studies, which reported values ranging from 7 to $27 \%{ }^{5}$.

The prolonged use of CLA in the treatment of other infections could be related to the selective pressure that results in the emergence of resistant microorganisms. The mutation $2143(\mathrm{~A} \rightarrow \mathrm{G})$ was detected in $85.7 \%(6 / 7)$ of samples, whereas only one strain had a mutation in the 2142 region $(A \rightarrow G)$. The predominance of the $A \rightarrow G$ mutation at sites 2142 and 2143 was suggested by Nash and Inderlied ${ }^{10}$ to be a result of the greater stability on the conformational change within the ribosome than mutations from $\mathrm{A} \rightarrow \mathrm{T}$ or $\mathrm{A} \rightarrow \mathrm{C}^{10,11}$. The mutation at position $2143(\mathrm{~A} \rightarrow \mathrm{G})$ of the $23 \mathrm{~S}$ rRNA gene has also been predominantly detected in other studies ${ }^{4,12}$. However, a large geographic variation can be observed, and an uneven distribution is possible even within a single country, highlighting the importance of characterizing the regional profiles of strains to provide a correct therapy ${ }^{13,14}$.

Regarding LVX, used as an alternative to conventional antimicrobials for the treatment of $\mathrm{H}$. pylori, we detected the presence of mutations in the gyrA gene in $22.5 \%(18 / 80)$ of the patients and these mutations confer LVX resistance. These results are similar to the ones found in another study carried out in Brazil ${ }^{14}$. The mutations were detected at positions Asn87 83.3\% (15/18) and Asp91 16.7\% (3/18) in $g y r A$. The presence of mutations in these regions also has been previously reported in several countries, including Brazil $^{3,8,15}$.

Several factors may be associated with antimicrobial resistance in $H$. pylori ${ }^{4}$. In this study, a significant association was detected among mutations related to resistance in patients older than 45 years old $(\mathrm{p}=0.024)$. The high consumption of these antimicrobials to treat other infections could explain why resistance to CLA and LVX is higher in older individuals, given the cumulative likelihood of exposure to these antimicrobials ${ }^{16}$.

While no significant association was observed between antimicrobial resistant and the absence of the cagA gene, $68 \%(17 / 25)$ of samples that were resistant to CLA or LVX were CagA-EPIYA-negative, whereas 20\% (5/25) had an $\mathrm{ABC}$ genotype, considered to have low pathogenicity, and only $12 \%$ (3/25) carried the ABCC/ABCCC genotype ${ }^{9}$.

Strains carrying the cagA gene develop an intense inflammatory response in the gastric epithelial cells and thus can proliferate more rapidly than $\operatorname{cag} A$-negative strains. As antimicrobials are primarily active upon bacteria during the logarithmic phase of growth, cagA-positive strains are probably more susceptible to antimicrobial activity than cagA-negative strains ${ }^{17}$. 
Antimicrobial pressure can cause a loss of specific virulence factors ( $c a g A)$ and lead to genetic rearrangements (loss or gain of EPIYA) that affect the impact of tyrosine phosphorylation, which can alter the pathogenic process of $H$. pylori in cases of treatment failure ${ }^{18}$. In this study, only four patients who were previously treated, presented therapeutic failure. Interestingly, all samples presented an endoscopic diagnosis of normal gastric mucosa or gastritis. In addition, these samples showed mutations associated with resistance to CLA or LVX, and 3 of 4 were cagA-negative. These data confirm the importance of cagA expression as a predictor of successful eradication, which was also reported by Russo et al. ${ }^{19}$.

In conclusion, in the population analyzed from the extreme South of Brazil, we observed high rates of antimicrobial resistance related to specific mutations, highlighting the importance of evaluating the antimicrobial resistance in circulating strains. Moreover, this study suggests a complex interplay involving the absence of the $\operatorname{cagA}$ pathogenicity marker and antimicrobial resistance, contributing to a deeper knowledge of H. pylori infection and clinical approaches for its treatment.

\section{ACKNOWLEDGMENTS}

We thank the Universidade Federal de Pelotas (UFPEL), Universidade Federal de Rio Grande (FURG), Hospital Universitario Sao Francisco de Paula (HUSFP); Dr. Heitor Alberto Jannke for the histological analysis.

\section{AUTHORS' CONTRIBUTION}

Júlia Silveira Vianna collected data, performed the experiments and wrote the article. Ivy Bastos Ramis, Daniela Fernandes Ramos and Pedro Eduardo Almeida da Silva oriented and critically reviewed the article. Otávio Leite Gastal and Renato Azevedo da Silva collected the gastric samples. Carla Vitola Gonçalves performed the statistical analysis

\section{REFERENCES}

1. Malfertheiner P, Megraud F, O’Morain CA, Gisbert JP, Kuipers EJ, Axon AT, et al. Management of Helicobacter pylori infection - the Maastricht V/Florence Consensus Report. Gut. 2017;66:6-30.

2. Versalovic J, Osato MS, Spakovsky K, Dore MP, Reddy R, Stone GG, et al. Point mutations in the 23S rRNA gene of Helicobacter pylori associated with different levels of CLA resistance. J Antimicrob Chemother. 1997;40:283-6.
3. Wang LH, Cheng H, Hu FL, Li J. Distribution of gyrA mutations in fluoroquinolone-resistant Helicobacter pylori strains. World J Gastroenterol. 2010;16:2272-7.

4. Agudo S, Pérez-Pérez G, Alarcón T, López-Brea M. High prevalence of CLA-resistant Helicobacter pylori strains and risk factors associated with resistance in Madrid, Spain. J Clin Microbiol. 2010;48:3703-7.

5. Vianna JS, Ramis IB, Ramos DF, Von Groll A, Silva PE. Drug resistance in Helicobacter pylori. Arq Gastroenterol. 2016;53:215-23.

6. Yamaoka Y, Kodama T, Kashima K, Graham DY, Sepulveda AR. Variants of the 3 region of the cagA gene in Helicobacter pylori isolates from patients with different H. pylori associated diseases. J Clin Microbiol. 1998;36:2258-63.

7. Burucoa C, Garnier M, Silvain C, Fauchère JL. Quadruplex real-time PCR assay using allele-specific scorpion primers for detection of mutations conferring CLA resistance to Helicobacter pylori. J Clin Microbiol. 2008;46:2320-6

8. Garcia M, Raymond J, Garnier M, Cremniter J, Burucoa C. Distribution of spontaneous gyrA Mutations in 97 fluoroquinolone-resistant Helicobacter pylori isolates collected in France. Antimicrob Agents Chemother. 2012;56:550-1.

9. Vianna JS, Ramis IB, Halicki PC, Gastal OL, Silva RA, Salomão $\mathrm{Jr}$ J, et al. Detection of Helicobacter pylori CagA EPIYA in gastric biopsy specimens and its relation to gastric diseases. Diagn Microbiol Infect Dis. 2015;83:89-92.

10. Nash KA, Inderlied CB. Genetic basis of macrolide resistance in Mycobacterium avium isolated from patients with disseminated disease. Antimicrob Agents Chemother. 1995;39:2625-30.

11. Debets-Ossenkopp YJ, Brinkman AB, Kuipers EJ, VandenbrouckeGrauls CM, Kusters JG. Explaining the bias in the 23S rRNA gene mutations associated with CLA resistance in clinical isolates of Helicobacter pylori. Antimicrob Agents Chemother. 1998;42:2749-51.

12. Suzuki RB, Lopes RA, Lopes GA, Ho TH, Sperança MA. Low Helicobacter pylori primary resistance to clarithromycin in gastric biopsy specimens from dyspeptic patients of a city in the interior of São Paulo, Brazil. BMC Gastroenterol. 2013;13:164.

13. Barile KA, Silva AL, Xavier JN, Assumpção MB, Corvelo TC. Characterization of $23 \mathrm{~S}$ rRNA domain $\mathrm{V}$ mutations in gastric biopsy patients from the eastern Amazon. Mem Inst Oswaldo Cruz. 2010;105:314-7.

14. Picoli SU, Mazzoleni LE, Fernández H, De Bona LR, Neuhauss E, Longo L, et al. Resistance to amoxicillin, clarithromycin and ciprofloxacin of Helicobacter pylori isolated from Southern Brazil patients. Rev Inst Med Trop Sao Paulo. 2014;56:197200.

15. Sanches BS, Martins GM, Lima K, Cota B, Moretzsohn LD, Ribeiro LT, et al. Detection of Helicobacter pylori resistance to CLA and fluoroquinolones in Brazil: A national survey. World J Gastroenterol. 2016;22:7587-94. 
16. Mégraud F. Current recommendations for Helicobacter pylori therapies in a world of evolving resistance. Gut Microbes. 2013;4:541-8.

17. Vilaichone RK, Mahachai V, Tumwasorn S, Wu JY, Graham DY, Yamaoka Y. Gastric mucosal cytokine levels in relation to host interleukin-1 polymorphisms and Helicobacter pylori cagA genotype. Scand J Gastroenterol. 2005;40:530-9.
18. Bustamante-Rengifo JA, Matta AJ, Pazos A, Bravo LE. In vitro effect of AMX and CLA on the 3' region of cagA gene in Helicobacter pylori isolates. World J Gastroenterol. 2013;19:6044-54.

19. Russo F, Berloco P, Cuomo R, Caruso ML, Di Matteo G, Giorgio $\mathrm{P}$, et al. Helicobacter pylori strains and histologically-related lesions affect the outcome of triple eradication therapy: a study from southern Italy. Aliment Pharmacol Ther. 2003;17:421-8.1 